\title{
Analysis of Reduced Monoclonal Antibodies Using Size Exclusion Chromatography Coupled with Mass Spectrometry
}

\author{
Hongcheng Liu, Georgeen Gaza-Bulseco, and Chris Chumsae \\ Process Sciences Department, Abbott Bioresearch Center, Worcester, Massachusetts, USA
}

\begin{abstract}
Size-exclusion chromatography (SEC) has been widely used to detect antibody aggregates, monomer, and fragments. SEC coupled to mass spectrometry has been reported to measure the molecular weights of antibody; antibody conjugates, and antibody light chain and heavy chain. In this study, separation of antibody light chain and heavy chain by SEC and direct coupling to a mass spectrometer was further studied. It was determined that employing mobile phases containing acetonitrile, trifluoroacetic acid, and formic acid allowed the separation of antibody light chain and heavy chain after reduction by SEC. In addition, this mobile phase allowed the coupling of SEC to a mass spectrometer to obtain a direct molecular weight measurement. The application of the SEC-MS method was demonstrated by the separation of the light chain and the heavy chain of multiple recombinant monoclonal antibodies. In addition, separation of a thioether linked light chain and heavy chain from the free light chain and the free heavy chain of a recombinant monoclonal antibody after reduction was also achieved. This optimized method provided a separation of antibody light chain and heavy chain based on size and allowed a direct measurement of molecular weights by mass spectrometry. In addition, this method may help to identify peaks eluting from SEC column directly. (J Am Soc Mass Spectrom 2009, 20, 2258-2264) (C) 2009 Published by Elsevier Inc. on behalf of American Society for Mass Spectrometry
\end{abstract}

$\mathrm{M}$ ass spectrometry is one of the most indispensable techniques for the characterization of recombinant monoclonal antibodies because most of the modifications that result in heterogeneity and degradation are involved in molecular weight differences [1,2]. Various modifications are determined by analyzing recombinant monoclonal antibodies at different levels, depending on the molecular weight differences of the modifications. Modifications, such as N-terminal glutamine and glutamate cyclization [3-9], different types of the conserved N-linked oligosaccharides [5, 7-13], amino acid truncation and insertion [8, 11], cysteinylation [14], C-terminal lysine processing [5, $7,11,15,16]$, fragmentation [12, 15, 17], glycation [18], oxidation [19, 20], and nitration [21] can be directly determined by measurements of the molecular weights of intact antibodies, antibody light chain and heavy chain, and Fab and Fc fragments after papain or lys-C digestion [14]. On the other hand, analysis at the peptide level is normally required to determine the sites of modifications and modifications with small molecular weight differences, such as deamidation $[22,23]$ and amidation [11], which results in a molecular weight difference of only $1 \mathrm{Da}$.

Address reprint requests to Dr. H. Liu, Process Sciences Department, Abbott Bioresearch Center, 100 Research Drive, Worcester, MA 01605, USA. E-mail: hongcheng.liu@abbott.com
Mass spectrometry is commonly coupled with reversedphase high-performance liquid chromatography (RPHPLC), which desalts the samples and separates different components based on hydrophobicity. The molecular weights of intact antibodies $[12,15]$ and their light chains and heavy chains can be readily measured by on-line RP-HPLC and mass spectrometry (MS) [9, 24]. However, high temperature and low $\mathrm{pH}$ are normally employed for elution, which can cause antibody degradation [9]. Sizeexclusion chromatography is commonly used for characterization and lot release of recombinant monoclonal antibody therapeutics. It is a robust method to measure the levels of aggregates, monomer, and fragments. However, the use of aqueous mobile phases containing various types and concentrations of salts prevents SEC from being coupled directly to mass spectrometry. In addition, separation of components that are linked by strong noncovalent interactions is not feasible. Nevertheless, size-exclusion chromatography has been applied to the analysis of intact molecular weights of antibodies and antibody conjugates $[25,26]$. The molecular weights of antibody light chain and heavy chain have also been determined using SEC-MS [26, 27]. Separation of the light chain and heavy chain of recombinant monoclonal antibodies with on-line mass spectrometry analysis was further optimized. Antibody light chain and heavy chain are connected by interchain disulfide bonds and strong noncovalent interactions. The interchain disulfide bonds can be easily reduced 
under native as well as denaturing conditions. Mobile phases that can prevent reformation of disulfide bonds and disrupt noncovalent interactions between the light chain and heavy chain are prerequisites for the separation of light chain and the heavy chain by SEC. For example, it has been reported that a mobile phase including $6 \mathrm{M}$ guanidine hydrochloride was sufficient to separate an antibody light chain, heavy chain, and a thioether linked species of the light chain and heavy chain [28]. However, denaturing reagents such as guanidine hydrochloride and urea in the mobile phases prevented a direct measurement of the molecular weights by SEC-MS because of the high salt concentration.

In the current study, separation of antibody light chain and heavy chain by SEC with direct coupling to a mass spectrometer to measure the molecular weights was further investigated. Separation of antibody light chain and heavy chain with mobile phases with different percentage of acetonitrile, trifluoroacetic acid, and formic acid was achieved, which also allowed a direct molecular weight measurement by mass spectrometry. The optimized SEC method with separation based on size differences provided an alternative to RP chromatography with separation based on hydrophobicity, which may have advantages over RP chromatography for some applications.

\section{Experimental}

\section{Materials and Methods}

Recombinant monoclonal antibodies A, B, C, D, and E were produced by transfected Chinese hamster ovary (CHO) cell lines and purified at Abbott Bioresearch Center, Worcester, MA, USA. Antibodies F and G were purchased from SouthernBiotech (Birmingham, AL, USA). Dithiothreitol (DTT) was purchased from Sigma (St. Louis, MO, USA). Acetonitrile and trifluoroacetic acid (TFA) were purchased from J. T. Baker (Phillipsburg, NJ, USA). Formic acid (FA) was purchased from EMD (Gibbstown, NJ, USA).

\section{Thermal Stress of Antibody}

Recombinant monoclonal antibody-A was diluted to 10 $\mathrm{mg} / \mathrm{mL}$ using deionized water using a Milli-Q system (Millipore, Bedford, MA, USA). The $\mathrm{pH}$ was adjusted to 10 using ammonium hydroxide. The sample was incubated at $40^{\circ} \mathrm{C}$ after sterile filtration using $0.2 \mu \mathrm{m}$ syringe filters (Gelman Sciences, Ann Arbor, MI, USA). Aliquots were taken every day up to $5 \mathrm{~d}$.

\section{Column Screening}

A Shimadzu HPLC was used to screen various columns including TSKgel G3000SW and TSKgel G3000SWxl from Tosoh Biosciences (Montgomeryville, PA, USA), Shodex KW-804, Protein-Pak 300SW, and BioSuite 250 from Waters (Milford, MA, USA). A mobile phase that con- tained $20 \%$ acetonitrile, $0.1 \%$ TFA, and $0.1 \%$ formic acid in Milli-Q water was employed for column screening. The flow-rate was set $0.2 \mathrm{~mL} / \mathrm{min}$ for columns with diameters of $7.5 \mathrm{~mm}$ and adjusted accordingly for columns with diameters of 7.8 or $8.0 \mathrm{~mm}$. The length of the columns tested was $300 \mathrm{~mm}$. Ambient temperature was used for SEC chromatography throughout the entire study. The sample was prepared by dilution of antibody-A to $1 \mathrm{mg} / \mathrm{mL}$ using $50 \mathrm{mM}$ Tris, $\mathrm{pH} 8.0$, and reduction with $10 \mathrm{mM}$ DTT at $37^{\circ} \mathrm{C}$ for $30 \mathrm{~min}$. Twenty $\mu \mathrm{g}$ of reduced antibody-A was injected into each column and separated by running the mobile phase for 80 min. Elution of proteins from the columns was monitored with UV absorption at $280 \mathrm{~nm}$.

\section{Comparison of Different Flow-Rates and Mobile Phase Compositions}

The TSKgel G3000SWxl column was selected for further method development, which, as will be discussed later, outperformed the other columns during the column screening. Separation of antibody-A light chain and heavy chain was compared using different flow rates, different percentages of acetonitrile, and different amounts of TFA. The flow rates of $0.5 \mathrm{~mL} / \mathrm{min}, 0.4$ $\mathrm{mL} / \mathrm{min}, 0.3 \mathrm{~mL} / \mathrm{min}$, and $0.1 \mathrm{~mL} / \mathrm{min}$ were compared using the mobile phase of $20 \%$ acetonitrile, $0.1 \%$ TFA, and $0.1 \%$ formic acid. Mobile phases containing $0 \%$, $10 \%, 20 \%, 30 \%, 40 \%$, and $50 \%$ acetonitrile with $0.1 \%$ TFA and $0.1 \%$ formic acid at a flow rate of $0.2 \mathrm{~mL} / \mathrm{min}$ were compared to determine the effect of acetonitrile on separation. The effect of TFA was determined using mobile phases containing $20 \%$ acetonitrile, $0.1 \%$ formic acid with $0 \%, 0.02 \%, 0.05 \%$, or $0.1 \%$ TFA at a flow rate of $0.2 \mathrm{~mL} / \mathrm{min}$. Twenty $\mu \mathrm{g}$ of antibody-A after reduction was injected onto the column for each condition. A run time of $80 \mathrm{~min}$ was used for all conditions and elution of proteins from the column was monitored by UV absorption at $280 \mathrm{~nm}$.

\section{Analysis of Different Antibodies by SEC}

The Shimadzu HPLC and the TSKgel G3000SWxl column with a mobile phase of $20 \%$ acetonitrile, $0.1 \%$ TFA, and $0.1 \%$ formic acid in Milli-Q water at a flow rate of 0.2 $\mathrm{mL} / \mathrm{min}$ for $80 \mathrm{~min}$ were used to analyze multiple antibodies. The samples were diluted to $1 \mathrm{mg} / \mathrm{mL}$ using 50 $\mathrm{mM}$ Tris, $\mathrm{pH} 8.0$, and reduced with $10 \mathrm{mM}$ DTT at $37^{\circ} \mathrm{C}$ for $30 \mathrm{~min}$. Twenty $\mu \mathrm{g}$ of each sample were injected. Elution was monitored using UV absorption at $280 \mathrm{~nm}$.

\section{Comparison of the Optimized SEC Method and Reversed-Phase Chromatography}

Comparison between the optimized SEC method and RP chromatography was made using antibody-A and antibody-A after thermal stress. The samples were reduced by following the procedure as described in the 
previous section. Antibody-A, reduced antibody-A, and a mixture consisting of equal portions of antibody- $\mathrm{A}$ and reduced antibody-A were analyzed using both the SEC method and RP chromatography. To prevent reduction of the intact antibody in the mixture, the sample was acidified using formic acid. Twenty $\mu \mathrm{g}$ of each sample was analyzed by SEC, while $50 \mu \mathrm{g}$ was analyzed by RP chromatography.

SEC was performed using the optimized conditions. For RP chromatography, the Shimadzu HPLC and a Vydac protein C4 column (4.6 mm i.d $\times 250 \mathrm{~mm}$ length) were used along with mobile phase A $(0.1 \%$ TFA in Milli-Q water) and mobile phase B (0.1\% TFA in acetonitrile). Samples were separated with the $\mathrm{C} 4$ column using a gradient of increasing mobile phase $\mathrm{B}$ from $5 \%$ to $20 \%$ in $5 \mathrm{~min}$, from $20 \%$ to $45 \%$ in $25 \mathrm{~min}$, and from $45 \%$ to $95 \%$ in $2 \mathrm{~min}$. The column was washed using 95\% mobile phase B for $6 \mathrm{~min}$ and then equilibrated using $5 \%$ mobile phase $B$ for $10 \mathrm{~min}$. The flow rate was set at $1 \mathrm{~mL} / \mathrm{min}$ and oven temperature was at set $60^{\circ} \mathrm{C}$. UV absorption at $280 \mathrm{~nm}$ was used to monitor the elution of protein peaks.

\section{SEC-MS}

The Shimadzu HPLC with the TSKgel G3000 SWxl column was used to separate and introduce samples into an Agilent Q-TOF mass spectrometer (Agilent, Santa Clara, CA, USA). The mobile phase was composed of $20 \%$ acetonitrile, $0.1 \%$ TFA and $0.1 \%$ formic acid in Milli-Q water. Antibody-A after thermal stress at $\mathrm{pH} 10$ for $5 \mathrm{~d}$ was diluted to $1 \mathrm{mg} / \mathrm{mL}$ using $50 \mathrm{mM}$ Tris, $\mathrm{pH} 8.0$, and reduced with $10 \mathrm{mM}$ DTT at $37^{\circ} \mathrm{C}$ for $30 \mathrm{~min}$. Five $\mu \mathrm{g}$ of the sample was loaded onto the column and separated at a flow rate of $0.2 \mathrm{~mL} / \mathrm{min}$ and introduced into the mass spectrometer directly. The mass spectrometer was operated in positive mode with a scan range from $\mathrm{m} / \mathrm{z} 600$ to 3200 , source temperature of $350{ }^{\circ} \mathrm{C}$, and Vcap voltage of $4750 \mathrm{~V}$.

\section{Results and Discussion}

\section{Comparison of Different Columns}

Several columns were evaluated using a mobile phase of $20 \%$ acetonitrile, $0.1 \%$ TFA, and $0.1 \%$ formic acid at a flow rate of $0.2 \mathrm{~mL} / \mathrm{min}$ for $80 \mathrm{~min}$. Separation of the light chain and heavy chain was achieved with all of the columns (Supplementary Figure 1, which can be found in the electronic version of this article). Identities of the light chain and heavy chain were confirmed by mass spectrometry analysis of the fractions collected from the SEC columns (data not shown). Theoretical plates of heavy chain and light chain and resolutions of heavy chain and light chain are summarized in Table 1. The TSKgel G3000SWxl column showed the second highest theoretical plate value for heavy chain, the highest theoretical plate value for light chain, and the highest resolution for heavy and light chain. Therefore, this column was selected for further optimization. It is worthwhile to mention that the column screening was only carried out under this specific condition, with one mobile phase and one flow-rate. Possibly, other columns may perform better under different conditions.

\section{Comparison of Different Flow Rates and Mobile Phase Compositions}

Flow rate modulates the velocity of molecules through the column and has a significant impact on resolution. This was observed again in the current study. Flow rates in the range of $0.1-0.5 \mathrm{~mL} / \mathrm{min}$ were tested using the mobile phase of $20 \%$ acetonitrile, $0.1 \%$ TFA, and $0.1 \%$ formic acid. As shown in Figure 1a, lower flow rates resulted in better resolution, as expected. However, broad peaks were observed when $0.1 \mathrm{~mL} / \mathrm{min}$ flow rate was employed, which indicated that this flow rate was too low for a column of this size. A lower flowrate is also necessary for a direct coupling of SEC to a mass spectrometer without a flow split. Therefore, the flow rate of $0.2 \mathrm{~mL} / \mathrm{min}$ was chosen for further investigation.

Acetonitrile assists desolvation of samples for mass spectrometry analysis. However, the solubility of proteins and salt components likely decrease with higher amounts of acetonitrile. Mobile phases with $0.1 \%$ TFA, $0.1 \% \mathrm{FA}$, and various percentages of acetonitrile were tested. Separation of the light chain and heavy chain was achieved using mobile phases containing $0 \%$ to $60 \%$ acetonitrile (Figure $1 \mathrm{~b}$ ). It was interesting to note that lower percentages of acetonitrile resulted in better

Table 1. Comparison of different columns

\begin{tabular}{|c|c|c|c|c|c|c|}
\hline \multirow[b]{2}{*}{ Columns } & \multirow[b]{2}{*}{ Dimensions (mm i.d. $\times$ mm length) } & \multirow[b]{2}{*}{ Particle size $(\mu \mathrm{m})$} & \multirow[b]{2}{*}{ Pore sizes $(\AA ̊)$} & \multicolumn{2}{|c|}{$\begin{array}{c}\text { Theoretical } \\
\text { plates }\end{array}$} & \multirow[b]{2}{*}{ Resolution } \\
\hline & & & & $\mathrm{HC}$ & LC & \\
\hline TSKgel G3000SW & $7.5 \times 300$ & 10 & 250 & 1980 & 3845 & 3 \\
\hline TSKgel G3000SWxI & $7.8 \times 300$ & 5 & 250 & 5060 & 10674 & 4 \\
\hline Shodex KW-804 & $8.0 \times 300$ & 7 & 250 & 4952 & 8859 & 2 \\
\hline Protein-Pak 300SW & $7.5 \times 300$ & 10 & 250 & 2078 & 4271 & 3 \\
\hline BioSuite 250 & $7.8 \times 300$ & 5 & 250 & 5149 & 9403 & 3 \\
\hline
\end{tabular}

Theoretical plate and resolution values were calculated using Shimadzu CLASS-VP software with the United States Pharmacopia (USP) calculation method. 
(a)

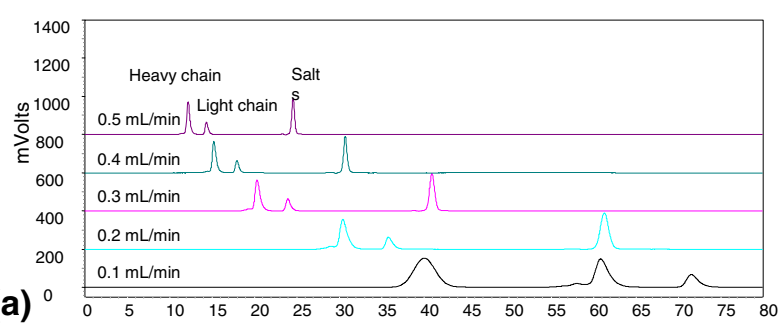

(b)
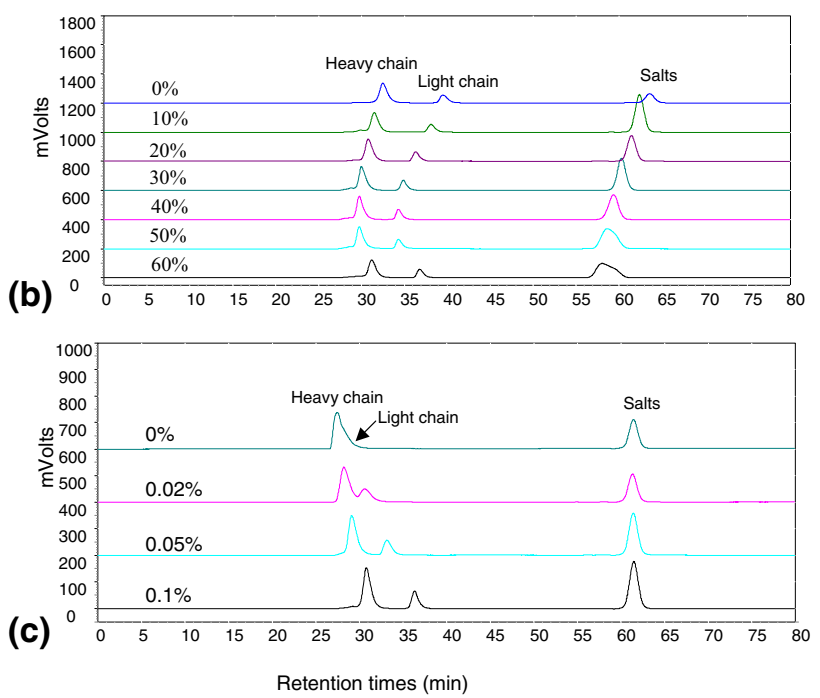

Figure 1. SEC chromatograms of antibody-A analyzed using TSKgel G3000SWxl column; (a) at various flow-rates of $0.5 \mathrm{~mL}$ / $\mathrm{min}, 0.4 \mathrm{~mL} / \mathrm{min}, 0.3 \mathrm{~mL} / \mathrm{min}, 0.2 \mathrm{~mL} / \mathrm{min}$, and $0.1 \mathrm{~mL} / \mathrm{min}$ as labeled in the figure; (b) using mobile phase consisting of $0 \%, 10 \%$, $20 \%, 30 \%, 40 \%, 50 \%$, or $60 \%$ acetonitrile as labeled in the figure with $0.1 \%$ TFA, and $0.1 \%$ formic acid in Milli-Q water; (c) using mobile phase consisting of $20 \%$ acetonitrile with $0.1 \%$ formic acid and with $0 \%, 0.02 \%, 0.05 \%$, or $0.1 \%$ TFA in Milli-Q water as labeled in the figure.

separation. Skewed salt peaks were observed when 50\% (Figure $1 \mathrm{~b}, 50 \%$ ) and $60 \%$ (Figure $1 \mathrm{~b}, 60 \%$ ) acetonitrile were used, which may suggest decreased solubility of the salts. It is worthwhile to mention that the retention times shifted with various percentages of acetonitrile. The retention times of the light chain and the heavy chain decreased with the increase of acetonitrile from $0 \%$ to $40 \%$, while the retention times of the light chain and the heavy chain increased from $40 \%$ to $60 \%$. On the other hand, the retention time of the salt peak decreased with the increase of acetonitrile from $0 \%$ to $60 \%$.

TFA is a common ion-pairing reagent that is often used to reduce the interactions of proteins with silica to obtain better resolution. However, it has been known that TFA suppresses mass spectrometry signal $[29,30]$. Therefore, the effect of using lower levels of TFA was investigated. As shown in Figure 1c, no separation of the light chain from the heavy chain was achieved if the mobile phase did not contain TFA (Figure 1c, $0 \%$ ). Separation of the light chain and the heavy chain improved with mobile phases containing increased levels of TFA from $0.02 \%$ to $0.1 \%$ (Figure 1c, $0.02 \%$, $0.05 \%$, and $0.1 \%$ ). The use of higher levels of TFA was not investigated due to its negative effect on mass spectrometry sensitivity.

\section{Analysis of Different Antibodies}

Five recombinant monoclonal antibodies (A-E) and two human IgG1 antibodies from patients with myeloma ( $\mathrm{F}$ and $\mathrm{G})$ were analyzed using the optimized condition, which included a mobile phase of $20 \%$ acetonitrile, $0.1 \%$ TFA, and $0.1 \%$ formic acid in Milli-Q water at a flowrate of $0.2 \mathrm{~mL} / \mathrm{min}$. The light chain and heavy chain of all antibodies were well separated (Supplementary Figure 2). Slight differences were observed between the retention times of the light chains of the different antibodies. The light chains of antibodies B, D, and G showed longer retention times compared to the light chains of antibodies A, C, E, and F. The light chain peaks of antibodies B, F, and $G$ were broader. The slight difference in retention time could not be due to molecular weight differences since all of the light chains were $\sim 23 \mathrm{kDa}$. Instead, the difference could be due to structural differences caused by the presence of acetonitrile and the low $\mathrm{pH}$ of the mobile phase or differences in hydrophobicity or interaction with the column stationary phase. Peaks with earlier retention times than the heavy chain were observed in antibodies F and G. The nature of these peaks was unknown, but they likely represented cross-linked species.

\section{Comparison of SEC and RP Chromatography}

In the first comparison, separation of antibody-A and its light chain and heavy chain was attempted using the optimized SEC method and RP chromatography. A significant peak tailing was observed for the peak at the retention time of $\sim 23 \mathrm{~min}$ when antibody-A was analyzed by RP chromatography (Figure 2a, intact). Antibody-A light chain and heavy chain were well separated with retention times of $\sim 20.5$ and $23 \mathrm{~min}$, respectively (Figure $2 \mathrm{a}$, reduced). However, intact antibody-A co-eluted with antibody-A heavy chain when reduced and intact antibody-A were analyzed together. This demonstrated that although intact antibody and antibody heavy chain had a significant molecular weight difference, they were not separated by RP chromatography, most likely due to similar hydrophobicity. In comparison, antibody-A and its light chain and heavy chain can be readily separated by the optimized SEC method as shown in Figure $2 b$.

In the second comparison, antibody-A after thermal stress was analyzed side-by-side using the optimized SEC method and RP chromatography. $\beta$-Elimination is a common degradation pathway of recombinant monoclonal antibodies [17, 28], which results in a nonreducible thioether linkage of the light chain and heavy chain. The linkage site was previously determined using material collected from SEC with $6 \mathrm{M}$ guanidine hydrochloride in the mobile phase [28]. Antibody-A was incubated at $\mathrm{pH} 10$ to facilitate the formation of the thioether linkage and then analyzed. When analyzed by 

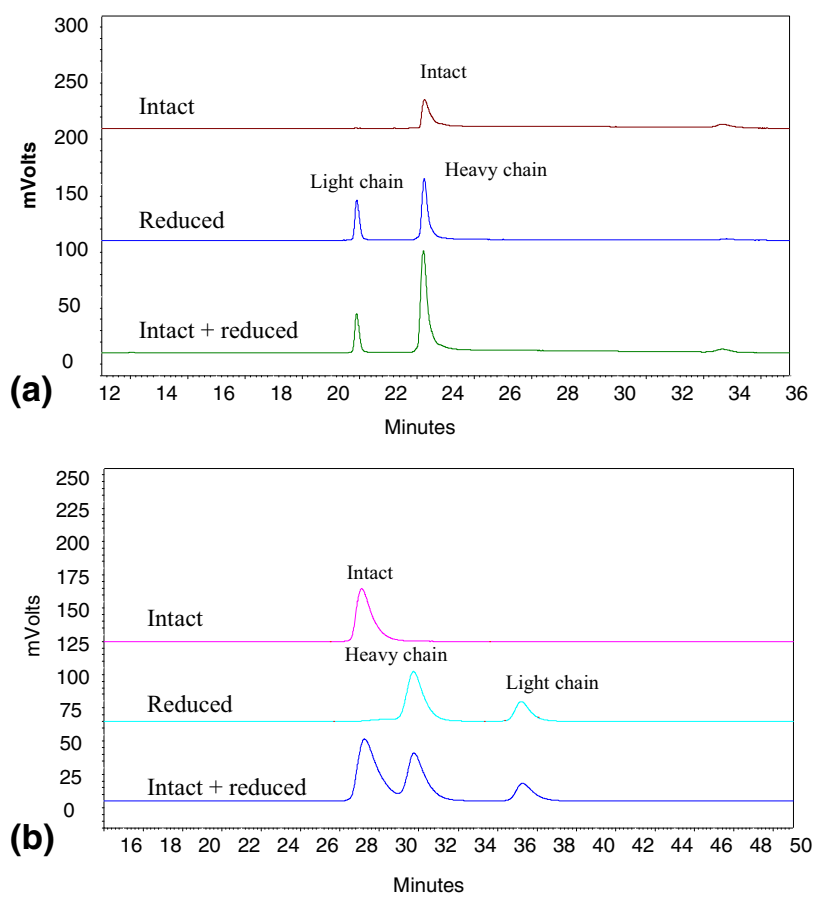

Figure 2. Comparison of SEC and reversed-phase chromatography using antibody-A. Antibody-A (intact), antibody-A after reduction (reduced), and a mixture containing both (intact + reduced) were analyzed by reversed-phase chromatography (a) and the optimized SEC method (b).

RP chromatography, antibody-A light chain and heavy chain eluted off the $\mathrm{C} 4$ column with retention times of $\sim 22.8$ and $26 \mathrm{~min}$, respectively (Figure $3 \mathrm{a}$ ). The intensity of the peak that was eluted off the column slightly earlier than the heavy chain increased with the increase of incubation time. This peak, as will be discussed later, corresponded to antibody-A light chain and heavy chain linked by a thioether bond. The fact that the cross linked species eluted between the light chain and heavy chain suggested that it was more hydrophobic than the light chain and less hydrophobic than the heavy chain. The stressed samples were also analyzed by SEC after reduction. Chromatograms of the samples are shown in Figure $3 b$. Intensity of the peak that eluted earlier than the heavy chain increased with the increase of incubation time. This peak, as also will be discussed in the following section, corresponded to the thioether linked light chain and heavy chain. Thus, the optimized SEC method resolved species that are different in molecular weight from the light chain and heavy chain without the use of chaotropic reagents such as guanidine hydrochloride.

\section{On-Line SEC-MS}

The use of mobile phase with $20 \%$ acetonitrile with TFA and formic acid allowed a direct coupling of SEC to a mass spectrometer. Measurement of the molecular weights of different components of antibody-A after stress for $5 \mathrm{~d}$ by SEC-MS was obtained. The column was run at $0.2 \mathrm{~mL} / \mathrm{min}$, which was directly coupled to the mass spectrometer without a flow-split. Total ion current chromatogram of the sample is shown in Figure 4. Three major peaks $(a-c)$ were observed in the total ion current chromatogram (Figure 4a). The mass spectra of peaks a to $\mathrm{c}$ are shown in Figure $4 \mathrm{~b}$. The theoretical molecular weights of antibody-A heavy chain without C-terminal Lys and with a core-fucosylated biantennary complex oligosaccharide structure without terminal galactose (G0) is $50,637 \mathrm{Da}$; with one terminal galactose (G1) is $50,799 \mathrm{Da}$. The light chain molecular weight of antibody-A is $23,408 \mathrm{Da}$. The observed molecular weights of peaks $\mathrm{b}$ and $\mathrm{c}$ were in agreement with the theoretical molecular weights of antibody-A heavy chain and light chain. Thus, peak $\mathrm{b}$ contained antibody-A heavy chain and peak c corresponded to antibody-A light chain. Peak a showed an observed molecular weight of 74,012 $\mathrm{Da}$. The calculated molecular weight of the heavy chain disulfide linked to the light chain was 74,043 $\mathrm{Da}(50,637+$ 23,408-2 protons because of the formation of the interchain disulfide bond). The observed molecular weight was 31 Da lower than the expected molecular weight of the heavy chain connected to the light chain by a disulfide bond, which corresponded to the loss of a sulfur atom $(32 \mathrm{Da})$. Thus, peak a contained a nonreducible species of antibody-A light chain and heavy chain as a result of $\beta$-elimination of the interchain disulfide bond and the formation of a thioether linkage. Degradation of disulfide bonds under basic conditions through $\beta$-elimination with the formation of thioether
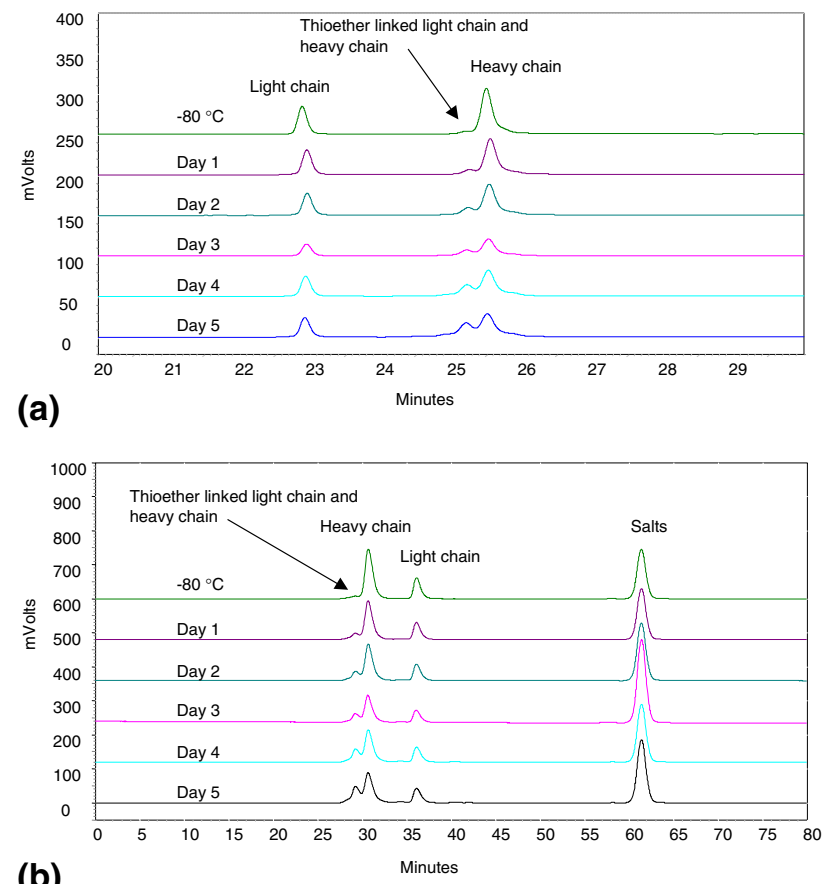

(b)

Figure 3. Comparison of SEC and reversed-phase chromatography using antibody-A after thermal stress. Antibody-A after incubation at $\mathrm{pH} 10$, at $40{ }^{\circ} \mathrm{C}$ for $0,1,2,3,4$, and $5 \mathrm{~d}$ were analyzed by reversed-phase chromatography (a) and the optimized SEC method (b). 


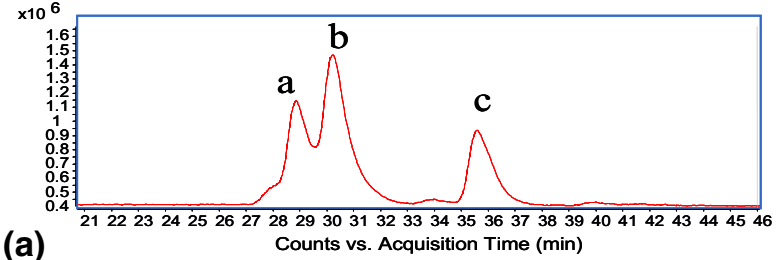

(a)
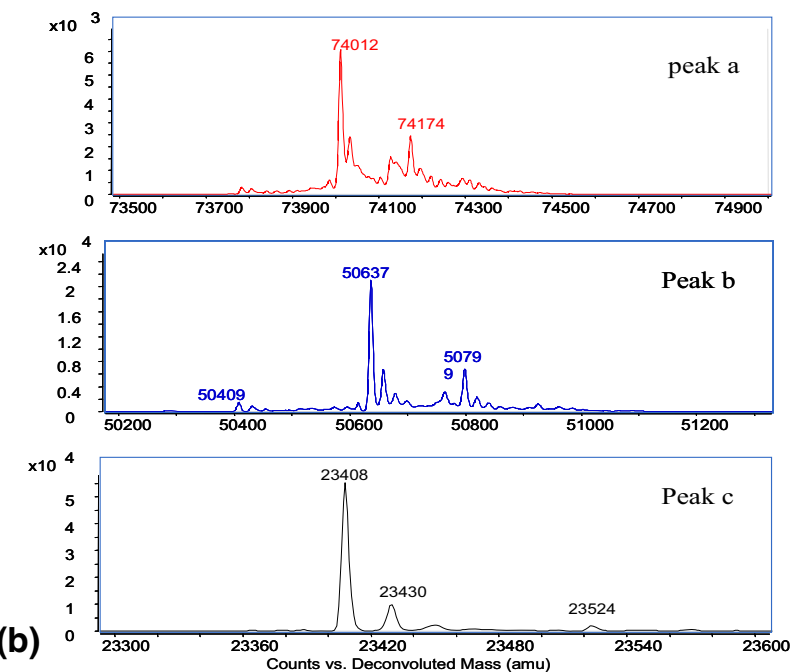

Figure 4. SEC-MS analysis of thermally stressed antibody-A. (a) Total ion current chromatogram of antibody-A after incubation at $\mathrm{pH} 10,40{ }^{\circ} \mathrm{C}$ for $5 \mathrm{~d}$. The major peaks are labeled as a, b and c. (b) Deconvoluted mass spectra of peaks $a, b$, and c.

linkage has been well documented in the literature [31-33] and reported for monoclonal antibodies [17, 28]. No interpretable mass spectrum was obtained for the shoulder that eluted in front of peak a. The small peak that eluted between peaks $b$ and $c$ had an observed molecular weight of $\sim 26,932 \mathrm{Da}$, which corresponded to antibody-A heavy chain amino acids 225-450 with an addition of a pyruval group, which resulted from peptide bond cleavage after $\beta$-elimination of the inter heavy chain and light chain disulfide bond [17].

\section{Conclusions}

An on-line SEC-MS method was optimized using a mobile phase consisting of acetonitrile, TFA, and formic acid. It was demonstrated that antibody light chain and heavy chain were well separated. In addition, this method was able to separate nonreducible cross-linked light chain and heavy chain species from free light chain and heavy chain. A flow-rate of $0.2 \mathrm{~mL} / \mathrm{min}$ was used in the current study and directly connected to the mass spectrometer. If lower flow-rates are necessary, the flow-rate can be decreased, split, or columns with smaller diameters could be used. The percentage of acetonitrile is also flexible as demonstrated in the study. This SEC-MS method provided several advantages over the commonly used RP-HPLC-MS and the previously reported SEC-MS methods. First, it optimized the previously reported SEC-MS method and can separate intact antibody, antibody light chain, heavy chain, and the thioether linked species. It has the potential to separate to covalent aggregates from monomeric antibodies and measure the molecular weights directly. Second, it avoided the use of high column temperature that is commonly employed for elution of RP chromatography and prevented protein degradation during separation. Third, it separated antibody light chain and heavy chain based, preponderantly, on their size difference rather than hydrophobicity. SEC-MS could provide complementary information to RP-HPLC-MS. In cases, where RP-chromatography is not sufficient, the SEC-MS may be applicable for separation. This optimized SEC-MS method has the potential to be applied to proteins other than antibodies.

\section{Acknowledgments}

The authors thank Peter Moesta and Gary Welch for their support.

\section{Appendix A Supplementary Material}

Supplementary material associated with this article may be found in the online version at doi:10.1016/ j.jasms.2009.08.015.

\section{References}

1. Liu, H.; Gaza-Bulseco, G.; Faldu, D.; Chumsae, C.; Sun, J. Heterogeneity of Monoclonal Antibodies. J. Pharm. Sci. 2008, 97(7), 2426-2447.

2. Wang, W.; Singh, S.; Zeng, D. L.; King, K.; Nema, S. Antibody Structure Instability, and Formulation. J. Pharm. Sci. 2007, 96(1), 1-26.

3. Yu, L.; Remmele, R. L., Jr.; He, B. Identification of N-Terminal Modification for Recombinant Monoclonal Antibody Light Chain Using Partial Reduction and Quadrupole Time-of-Flight Mass Spectrometry. Rapid Commun. Mass Spectrom. 2006, 20(24), 3674-3680.

4. Yu, L.; Vizel, A.; Huff, M. B.; Young, M.; Remmele, R. L., Jr.; He, B. Investigation of N-Terminal Glutamate Cyclization of Recombinant Monoclonal Antibody in Formulation Development. J. Pharm. Biomed Anal. 2006, 42(4), 455-463.

5. Wang, L.; Amphlett, G.; Lambert, J. M.; Blattler, W.; Zhang, W. Structural Characterization of a Recombinant Monoclonal Antibody by Electrospray Time-of-Flight Mass Spectrometry. Pharm. Res. 2005, 22(8), 1338-1349.

6. Chelius, D.; Jing, K.; Lueras, A.; Rehder, D. S.; Dillon, T. M.; Vizel, A.; Rajan, R. S.; Li, T.; Treuheit, M. J.; Bondarenko, P. V. Formation of Pyroglutamic Acid from N-Terminal Glutamic Acid in Immunoglobulin $\gamma$ Antibodies. Anal. Chem. 2006, 78(7), 2370-2376.

7. Lyubarskaya, Y.; Houde, D.; Woodard, J.; Murphy, D.; Mhatre, R. Analysis of Recombinant Monoclonal Antibody Isoforms by Electrospray Ionization Mass Spectrometry as a Strategy for Streamlining Characterization of Recombinant Monoclonal Antibody Charge Heterogeneity. Anal. Biochem. 2006, 348(1), 24-39.

8. Beck, A.; Bussat, M. C.; Zorn, N.; Robillard, V.; Klinguer-Hamour, C. Chenu, S.; Goetsch, L.; Corvaia, N.; Van Dorsselaer, A.; Haeuw, J. F. Characterization by Liquid Chromatography Combined with Mass Spectrometry of Monoclonal Anti-IGF-1 Receptor Antibodies Produced in CHO and NS0 Cells. J. Chromatogr. B Analyt. Technol. Biomed. Life Sci. 2005, 819(2), 203-218.

9. Rehder, D. S.; Dillon, T. M.; Pipes, G. D.; Bondarenko, P. V. ReversedPhase Liquid Chromatography/Mass Spectrometry Analysis of Reduced Monoclonal Antibodies in Pharmaceutics. J. Chromatogr. A 2006 1102(1/2), 164-175.

10. Siemiatkoski, J.; Lyubarskaya, Y. Houde, D.; Tep, S.; Mhatre, R. A Comparison of Three Techniques for Quantitative Carbohydrate Analysis Used in Characterization of Therapeutic Antibodies. Carbohydr. Res. 2006, 341(3), 410-419.

11. Johnson, K. A.; Paisley-Flango, K.; Tangarone, B. S.; Porter, T. J.; Rouse, J. C. Cation Exchange-HPLC and Mass Spectrometry Reveal C-Terminal Amidation of an IgG1 Heavy Chain. Anal. Biochem. 2007, 360(1), 75-83.

12. Dillon, T. M.; Bondarenko, P. V.; Rehder, D. S.; Pipes, G. D.; Kleemann, G. R.; Ricci, M. S. Optimization of a Reversed-Phase High-Performance Liquid Chromatography/Mass Spectrometry Method for Characteriz- 
ing Recombinant Antibody Heterogeneity and Stability. J. Chromatogr. A 2006, 1120(1/2), 112-120.

13. Lim, A.; Reed-Bogan, A.; Harmon, B. J. Glycosylation Profiling of a Therapeutic Recombinant Monoclonal Antibody with Two N-Linked Glycosylation Sites Using Liquid Chromatography Coupled to a Hybrid Quadrupole Time-of-Flight Mass Spectrometer. Anal. Biochem. 2008, 375(2), 163-172.

14. Gadgil, H. S.; Bondarenko, P. V.; Pipes, G. D.; Dillon, T. M.; Banks, D.; Abel, J.; Kleemann, G. R.; Treuheit, M. J. Identification of Cysteinylation of a Free Cysteine in the Fab Region of a Recombinant Monoclonal IgG1 Antibody Using Lys-C Limited Proteolysis Coupled with LC/MS Analysis. Anal. Biochem. 2006, 355(2), 165-174.

15. Dillon, T. M.; Bondarenko, P. V.: Speed Ricci, M. Development of an Analytical Reversed-Phase High-Performance Liquid ChromatographyElectrospray Ionization Mass Spectrometry Method for Characterization of Recombinant Antibodies. J. Chromatogr. A 2004, 1053(1/2), 299-305.

16. Antes, B.; Amon, S.; Rizzi, A.; Wiederkum, S.; Kainer, M.; Szolar, O.; Fido, M.; Kircheis, R.; Nechansky, A. Analysis of Lysine Clipping of a Humanized Lewis-Y Specific IgG Antibody and its Relation to FcMediated Effector Function. J. Chromatogr. B Analyt. Technol. Biomed. Life Sci. 2007, 852(1/2), 250-256.

17. Cohen, S. L.; Price, C.; Vlasak, J. $\beta$-Elimination and Peptide Bond Hydrolysis: Two Distinct Mechanisms of Human IgG1 Hinge Fragmentation Upon Storage. J. Am. Chem. Soc. 2007, 129(22), 6976-6977.

18. Zhang, B.; Yang, Y.; Yuk, I.; Pai, R.; McKay, P.; Eigenbrot, C.; Dennis, M.; Katta, V.; Francissen, K. C. Unveiling a Glycation Hot Spot in a Recombinant Humanized Monoclonal Antibody. Anal. Chem. 2008, 80(7), 2379-2390.

19. Chumsae, C.; Gaza-Bulseco, G.; Sun, J.; Liu, H. Comparison of Methionine Oxidation in Thermal Stability and Chemically Stressed Samples of a Fully Human Monoclonal Antibody. J. Chromatogr. B Analyt. Technol. Biomed. Life Sci. 2007, 850(1/2), 285-294.

20. Liu, H.; Gaza-Bulseco, G.; Zhou, L. Mass Spectrometry Analysis of Photo-Induced Methionine Oxidation of a Recombinant Human Monoclonal Antibody. J. Am. Soc. Mass Spectrom. 2009, 20(3), 525-528.

21. Liu, H.; Gaza-Bulseco, G.; Chumsae, C.; Radziejewski, C. H. Mass Spectrometry Analysis of In Vitro Nitration of a Recombinant Human IgG1 Monoclonal Antibody. Rapid Commun. Mass Spectrom. 2008, 22(1), $1-10$.
22. Gaza-Bulseco, G.; Li, B.; Bulseco, A.; Liu, H. Method to Differentiate Asn Deamidation that Occurred Prior to and During Sample Preparation of a Monoclonal Antibody. Anal. Chem. 2008, 80(24), 9491-9498.

23. Chelius, D.; Rehder, D. S.; Bondarenko, P. V. Identification and Characterization of Deamidation Sites in the Conserved Regions of Human Immunoglobulin $\gamma$ Antibodies. Anal. Chem. 2005, 77(18), 6004-6011.

24. Liu, H.; Gaza-Bulseco, G.; Lundell, E. Assessment of Antibody Fragmentation by Reversed-Phase Liquid Chromatography and Mass Spectrometry. J. Chromatogr. B Analyt. Technol. Biomed. Life Sci. 2008, 876(1), $13-23$.

25. Lazar, A. C.; Wang, L.; Blattler, W. A.; Amphlett, G.; Lambert, J. M. Zhang, W. Analysis of the Composition of Immunoconjugates Using Size-Exclusion Chromatography Coupled to Mass Spectrometry. Rapid Commun. Mass Spectrom. 2005, 19(13), 1806-1814.

26. Brady, L. J.; Valliere-Douglass, J.; Martinez, T.; Balland, A. Molecular Mass Analysis of Antibodies by On-Line SEC-MS. J. Am. Soc. Mass Spectrom. 2008, 19(4), 502-509.

27. Lazar, A. C.; Kloczewiak, M. A.; Mazsaroff, I. Size-Exclusion Chromatography Online-Coupled to Electrospray Mass Spectrometry for the Analysis of the Light and Heavy Chains of Recombinant IgG1 Molecules. Proceedings of the 52nd ASMS Conference on Mass Spectrometry and Allied Topics; Nashville, TN, May, 2004.

28. Tous, G. I.; Wei, Z.; Feng, J.; Bilbulian, S.; Bowen, S.; Smith, J.; Strouse, R.; McGeehan, P.; Casas-Finet, J.; Schenerman, M. A. Characterization of a Novel Modification to Monoclonal Antibodies: Thioether Cross-Link of Heavy and Light Chains. Anal. Chem. 2005, 77(9), 2675-2682.

29. Mirza, U. A. Chait, B. T. Effects of Anions on the Positive Ion Electrospray Ionization Mass Spectra of Peptides and Proteins. Anal. Chem. 1994, 66(18), 2898-2904.

30. Apffel, A.; Fischer, S.; Goldberg, G.; Goodley, P. C.; Kuhlmann, F. E. Enhanced Sensitivity for Peptide Mapping with Electrospray Liquid Chromatography-Mass Spectrometry in the Presence of Signal Suppression Due to Trifluoroacetic Acid-Containing Mobile Phases. J. Chromatogr. A 1995, 712(1), 177-190.

31. Nashef, A. S.; Osuga, D. T.; Lee, H. S.; Ahmed, A. I.; Whitaker, J. R.; Feeney, R. E. Effects of Alkali on Proteins. Disulfides and Their Products. J. Agric. Food Chem. 1977, 25(2), 245-251.

32. Florence, T. M. Degradation of Protein Disulphide Bonds in Dilute Alkali. Biochem. J. 1980, 189(3), 507-520.

33. Galande, A. K.; Trent, J. O.; Spatola, A. F. Understanding Base-Assisted Desulfurization Using a Variety of Disulfide-Bridged Peptides. Biopolymers 2003, 71(5), 534-551. 